\title{
Ventilation coefficient trends in the recent decades over four major Indian metropolitan cities
}

\author{
U S IYER* and P ERNEST RAJ \\ Indian Institute of Tropical Meteorology, Dr. Homi Bhabha Road, Pashan, Pune 411 008, India. \\ ${ }^{*}$ Corresponding author. e-mail: usha@tropmet.res.in
}

Thirty years radiosonde data (1971-2000) at 00 UTC for winter months over four major Indian metros, viz., Mumbai, Delhi, Kolkata and Chennai is analysed to study the trends and long term variations in ventilation coefficients and the consequences on the air quality due to these variations in the four metros. A decreasing trend in ventilation coefficient is observed in all the four metros during the 30 years period indicating increasing pollution potential and a degradation in the air quality over these urban centers. In Delhi, the ventilation coefficient decreased at the rate of 49 and $32 \mathrm{~m}^{2} / \mathrm{s} /$ year in the months of December and February, respectively during the 30-year period. In Mumbai, the average decrease in ventilation coefficient in winter months is about $15 \mathrm{~m}^{2} / \mathrm{s} /$ year whereas for Kolkata it is 14 and $17 \mathrm{~m}^{2} / \mathrm{s} /$ year in December and February, respectively. A decreasing trend in ventilation coefficient is observed in Chennai too although it is not significant. The decreasing ventilation coefficient increased the ground level pollution thereby deteriorating the air quality for the urban population. For Mumbai and Kolkata, decreasing mixing depths and decreasing wind speed contributed to the decreasing ventilation coefficient whereas for Delhi and Chennai decreasing wind speed was responsible for the decrease in ventilation coefficient. Further, the pollution potential was much higher in Delhi which is an inland station as compared to Mumbai, Kolkata and Chennai which are coastal stations under the influence of marine environment. Compared to Delhi, the pollution potential over these three metros was lower as the prevailing sea-breeze helped in the dispersal of pollutants thereby reducing their ground level concentration.

\section{Introduction}

Metropolitan cities all over the world are characterized by their economic development and large population resulting in increased human activity that, in turn, can lead to high pollution levels. Consequently, the air quality in these cities is severely affected. The ventilation coefficient, which is the product of mixing depth and the average wind speed, is an atmospheric condition which gives an indication of the air quality and pollution potential, i.e., the ability of the atmosphere to dilute and disperse the pollutants over a region. The higher the coefficient, the more efficiently the atmosphere is able to dispose the pollutants and better is the air quality. On the other hand, low ventilation coefficients lead to poor dispersal of pollutants causing stagnation and poor air quality leading to possible pollution related hazards. The ventilation coefficient is a function of mixing depth and the average wind speed through the mixing layer. A fluctuation in the values of either/both these quantities causes a variation in the ventilation coefficient.

Several studies have documented the variations in ventilation coefficient over different regions in India as well as in other parts of the world. Various

Keywords. Air quality; mixing depth; pollution potential; ventilation coefficient. 
methods have been employed to calculate/derive the mixing depths (required to compute ventilation coefficients) from lidar observations (Ernest Raj and Devara 1992) or sodar (Goyal et al. 2006) or wind profiler (Krishnan and Kunhikrishnan 2004) or by following the profile intersection technique proposed by Holzworth (1967) (Padmanabhamurthy and Mandal 1979; Padmanabhamurthy and Tangirala 1990). Radiosondes or pilot balloons have been used for wind observations in most of the studies. In India, it was generally observed that ventilation coefficients were higher in pre-monsoon months and lower during southwest monsoon and winter months. Diurnal variation of ventilation coefficient showed that assimilative capacity (determined in terms of the ventilation coefficient) of the atmosphere is high during afternoon hours and it gets reduced during evening and morning hours in summer and winter. The season having the poorest assimilative capacity is winter. Due to low mixing depths and low wind speeds, the ventilation coefficients in winter are much lower which increases the ground level pollutant concentration as compared to other months. Low mixing heights are observed in India during monsoon and winter seasons (Devara and Ernest Raj 1993; Krishnan and Kunhikrishnan 2004). But due to strong prevailing winds during monsoons, pollutants are dispersed and washed out by rain, thus, low ventilation coefficient does not necessarily indicate high pollution in this season. In winter, however, weak winds are observed and pollutants are not dispersed. They get trapped below the stable layer which acts as capping to mixed layer, leading to higher ground level concentration of pollutants. The variations in mixing depth and wind speeds thus significantly impact the air quality over a region.

According to the National Meteorological Centre, USA and Atmospheric Environment Services, Canada, the criteria for the occurrence of high
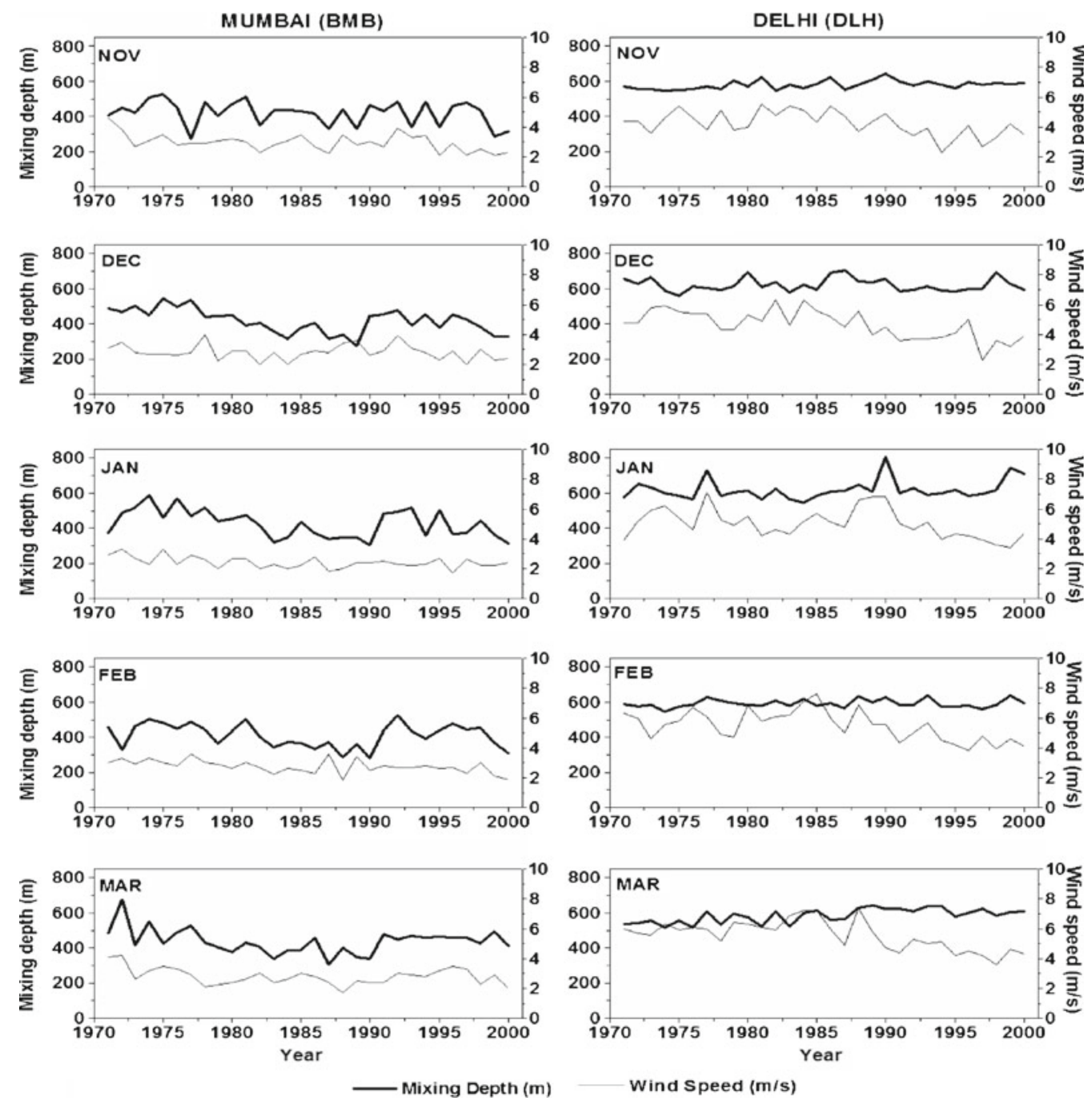

Figure 1(a). Annual variations in mixing depth and wind speed through mixing layer for the months November--March for Mumbai and Delhi. 
pollution potential is that, the afternoon ventilation coefficient is less than $6000 \mathrm{~m}^{2} / \mathrm{s}$ and mean wind speed is less than $4 \mathrm{~m} / \mathrm{s}$. During morning hours, mixing heights less than $500 \mathrm{~m}$ and mean wind speed less than $4 \mathrm{~m} / \mathrm{s}$ is the criteria (Stack Pole 1967; Gross 1970) for the occurrence of high pollution potential.

Several researchers, viz., Padmanabhamurthy and Mandal (1979), Alappattu et al. (2009) etc., have studied the assimilative capacity, dispersal capacity and pollution potential in terms of the variations in ventilation coefficients over different locations in India. However, they are limited to short periods of time. In a recently published Atlas of hourly mixing height and assimilative capacity of atmosphere in India, Attri et al. (2008) have used IMD (India Meteorological Department) data to calculate mixing heights and ventilation coefficients for the period 1990-1999 over 31 RS/RW stations during winter, pre-monsoon and post-monsoon seasons. The spatial distribution of mixing heights in winter at 07.00 IST is about 40-80 m in Mumbai, Delhi, Kolkata and Chennai. The ventilation coefficient is between 205 and $345 \mathrm{~m}^{2} / \mathrm{s}$ for Mumbai, Delhi and Chennai and around $125-205 \mathrm{~m}^{2} / \mathrm{s}$ for Kolkata.

Ventilation coefficient is an indicator of air quality over any location. Long term variations in ventilation coefficients have not been addressed over the Indian region. The objective of our study is to document the changes and long term-trends in ventilation coefficients over four major Indian metropolitan cities, viz., Mumbai (BMB), Delhi (DLH), Kolkata (CAL) and Chennai (MDS) and discuss its impact on the air quality in these cities. For this we have considered data for a period of 30 years from 1971 to 2000. Three out of these four cities, viz., BMB, CAL and MDS are coastal stations under the influence of marine environment while DLH is an inland station far away from the coast with no coastal influence. The data and methodology used are described in section 2 ,
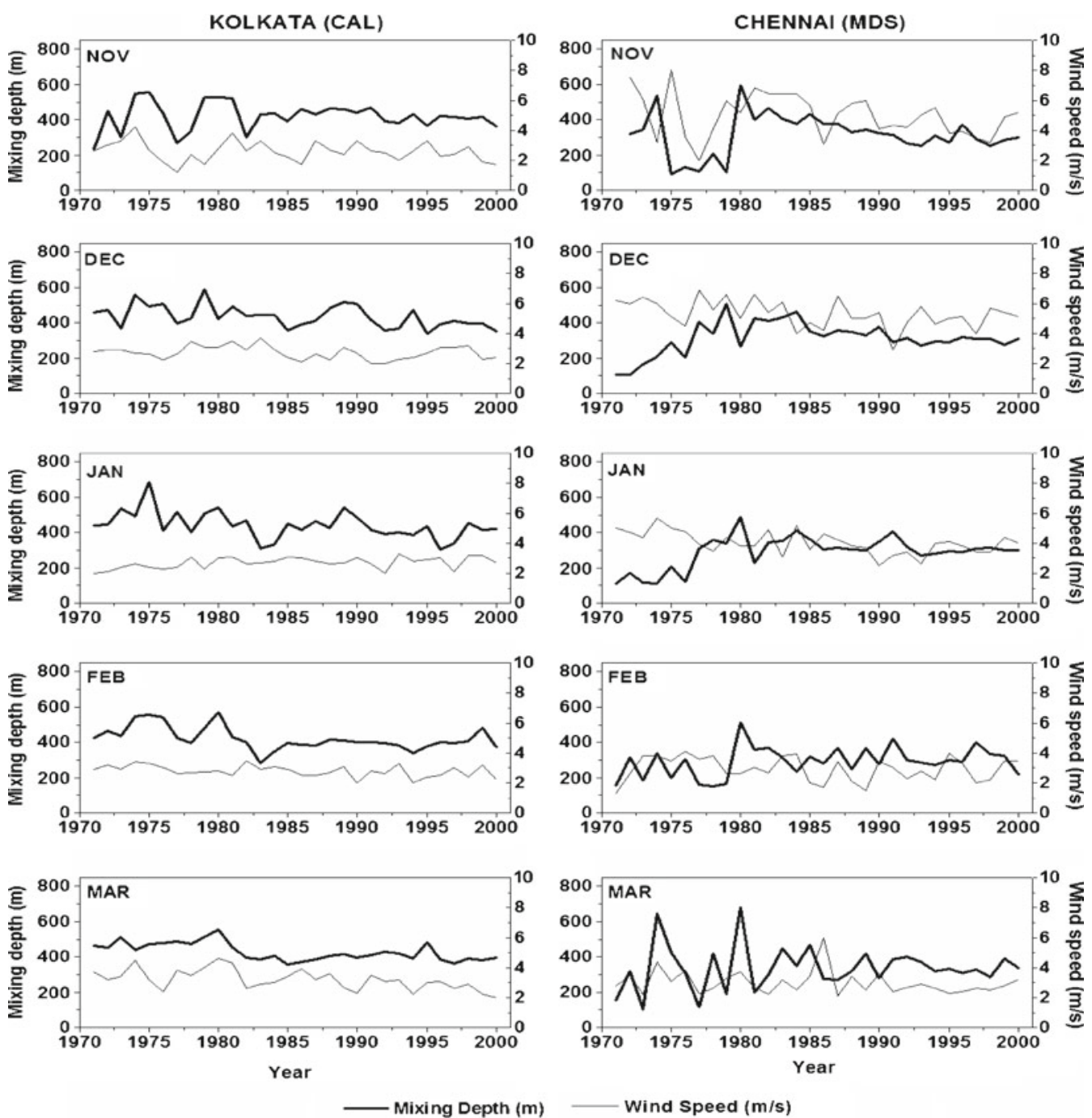

Figure 1(b). As in figure 1(a) but for kolkata and Chennai. 
analyses of the results are presented in section 3 and sub-sections contained therein. Finally, the conclusions are given in section 4 .

\section{Data and methodology}

Daily radiosonde data at 00 UTC for 30 years (1971-2000) for the months of November, December, January, February and March for the four Indian metros $\mathrm{BMB}\left(18.55^{\circ} \mathrm{N}, 72.54^{\circ} \mathrm{E}\right), \mathrm{DLH}$ $\left(28.38^{\circ} \mathrm{N}, 77.12^{\circ} \mathrm{E}\right), \mathrm{CAL}\left(22.34^{\circ} \mathrm{N}, 88.24^{\circ} \mathrm{E}\right)$ and MDS $\left(13.04^{\circ} \mathrm{N}, 80.17^{\circ} \mathrm{E}\right)$ are analysed to derive mixing depths and then compute ventilation coefficients. The data is obtained from IMD, Pune. To avoid inconsistencies in data caused by instrument change, we have used data from 1971 onwards when uniform data was available as the Chronometric
(C) and Fan (F) type sondes were replaced by Audio Modulated (AM) type sondes (Kothawale and Rupa Kumar 2002). Observations of atmospheric variables are made by these balloon-borne radiosondes up to $20-25 \mathrm{~km}$ with an interval of roughly $500 \mathrm{~m}$ (standard levels). In addition, we have incorporated significant level data in between the standard level data so that we have observations at a higher resolution. Though significant levels are not fixed, we found, on an average one significant level occurred between two standard levels and we were able to get temperature observations at an interval of about 200-250 m. For significant level winds, we have linearly interpolated the wind data from the nearest standard level. Though wind does not vary linearly with height, we feel that since we have considered data up to $\sim 2 \mathrm{~km}$ only, errors may be negligible. Before permanent
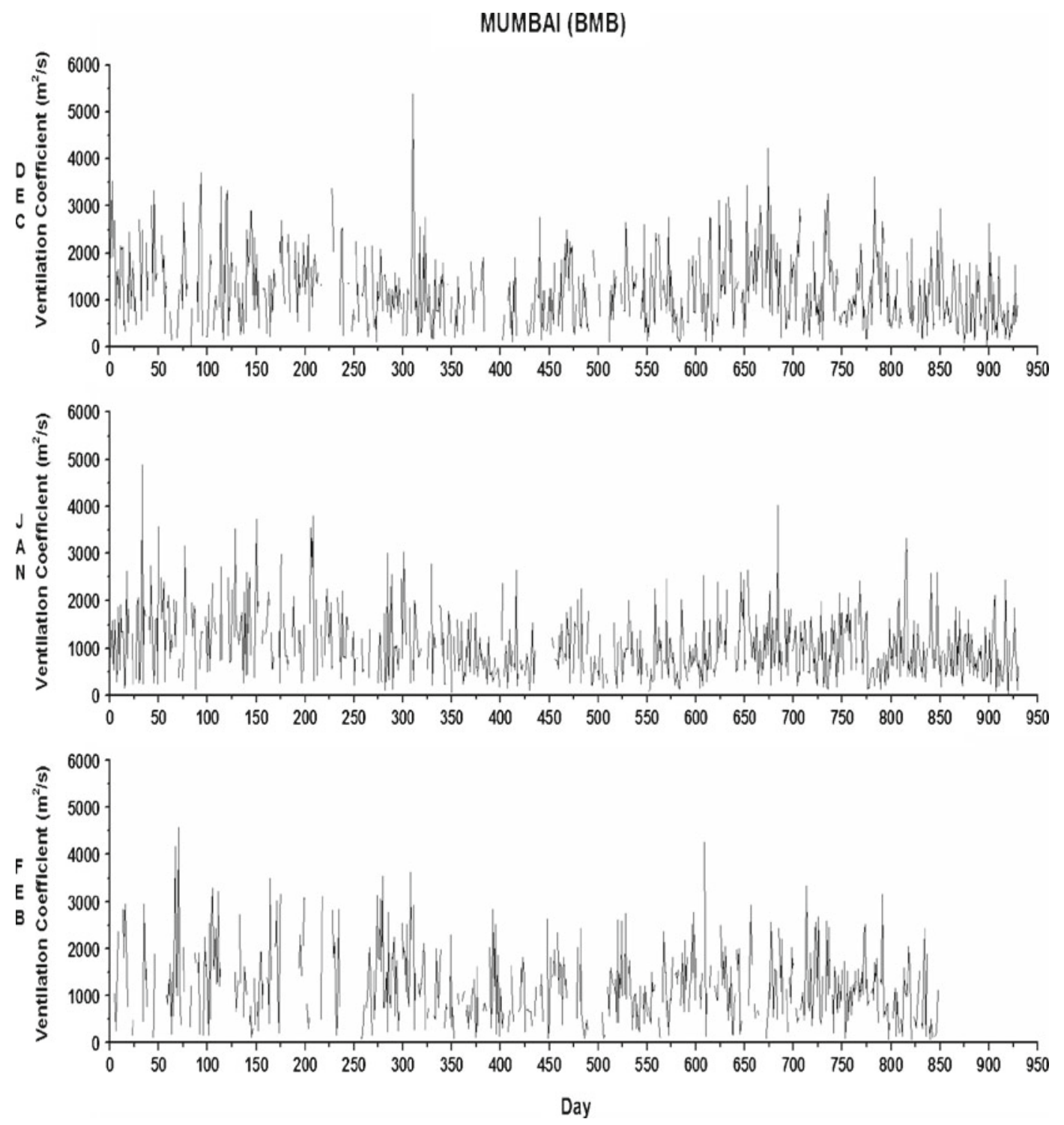

Figure 2(a). Day-to-day variations in ventilation coefficient during December, January and February for 30 years for Mumbai. 
archival, the data is processed and several checks applied to ensure homogeneity (Srivastava et al. 1992). Despite these checks, inconsistencies do occur, thus, before analyzing we have discarded data whenever abnormal values were found by following the method of Ananthakrishnan and Soman (1992). Each value was checked with the mean and if at any level it differed from the respective mean by more than three times the standard deviation then was discarded.

The mixing depth is broadly defined as the height above the surface through which relatively vigorous vertical mixing occurs (Holzworth 1967; Berman et al. 1999; Manju et al. 2002). The boundary layer is generally stable at night due to radiational cooling of the ground consequently, vertical mixing is frequently minimal. In such cases, Berman et al. (1999) have suggested that the height of the surface inversion may be used as a measure of the depth of the mixed layer. Therefore for calculating mixing depths, we have followed this method wherein the height of the surface inversion is taken as the height of the mixed layer. If there is an increase in temperature with height from the surface, then it was considered as surface inversion. The height at which the temperature again begins to decrease is taken as the height of the surface inversion. This height of the surface inversion is taken as mixing height. The mean wind speed in this layer is computed as a simple average of wind speed at the surface and at the top of the mixed layer (Padmanabhamurthy and Mandal 1979).

\section{DELHI (DLH)}
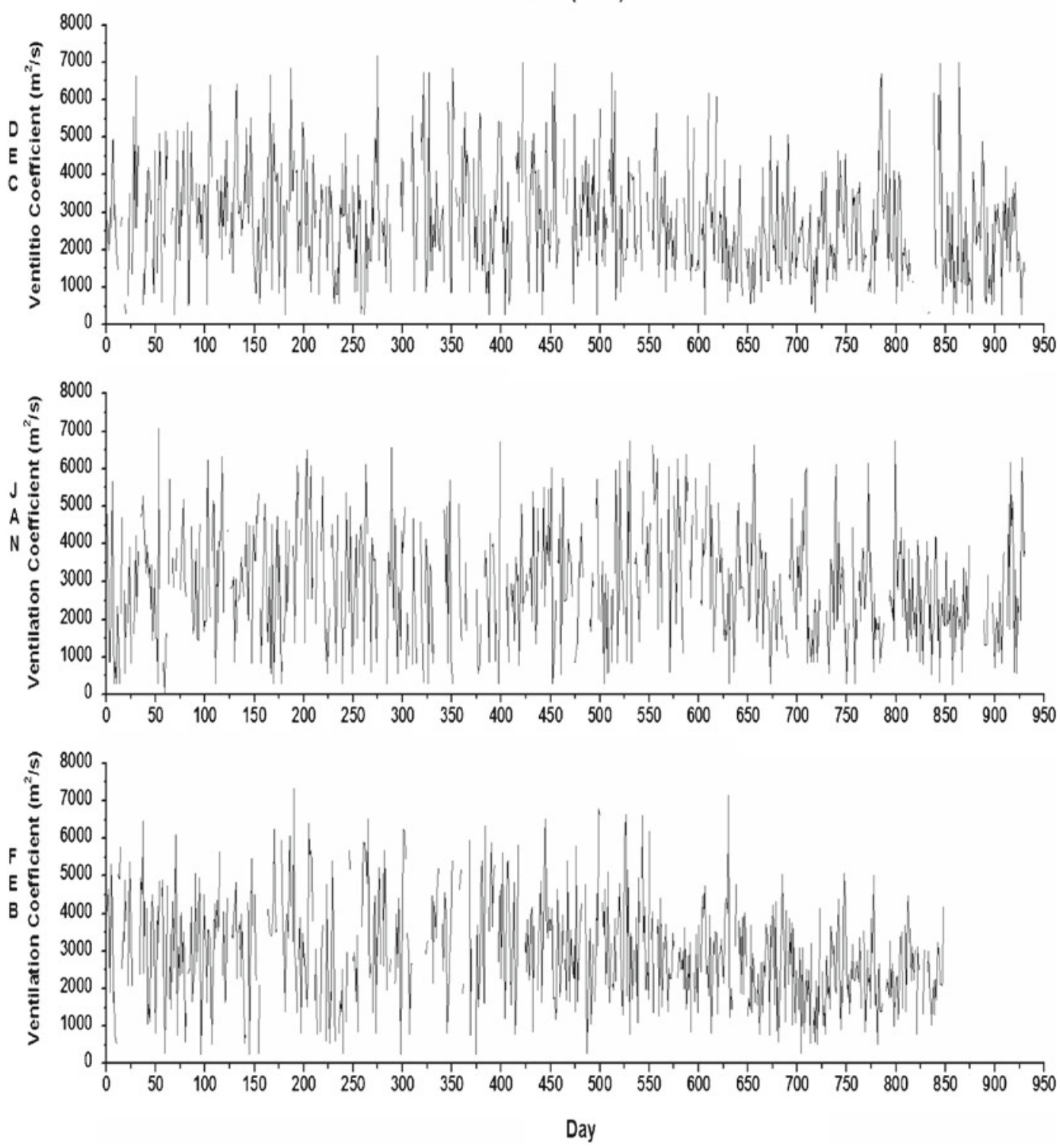

Figure 2(b). As in figure 2(a) but for Delhi. 
The ventilation coefficient $(V C)$ is then computed as:

$$
V C=[\text { mixing depth } \times \text { mean wind speed }] .
$$

Monthly averages are calculated from the available daily values for each year of the 30-year period to analyze the variations. The coefficient of variation (expressed in \%) for the peak winter months (December, January and February) are computed as:

$$
C V=[\text { standard deviation } / \text { mean }] \times 100 .
$$

$C V$ is a measure of the variability relative to the mean; larger values indicate greater variability (Berman et al. 1999).

\section{Results and discussion}

\subsection{Variations in mixing depths and wind speed through the mixing layer}

Adopting the aforementioned methodology, mixing depth at 00 UTC on each day has been derived for the four metropolitan cities in India. The monthly mean mixing depth and mean wind speed in the mixing layer are computed separately for the months of November, December, January, February and March during each year and the year-to-year variations are plotted in figure 1(a) for Mumbai (BMB) and Delhi (DLH) and in figure 1 (b) for Kolkata (CAL) and Chennai (MDS). For BMB, the mixing depths are in the range of 300-500 m with a mean depth of about $420 \mathrm{~m}$
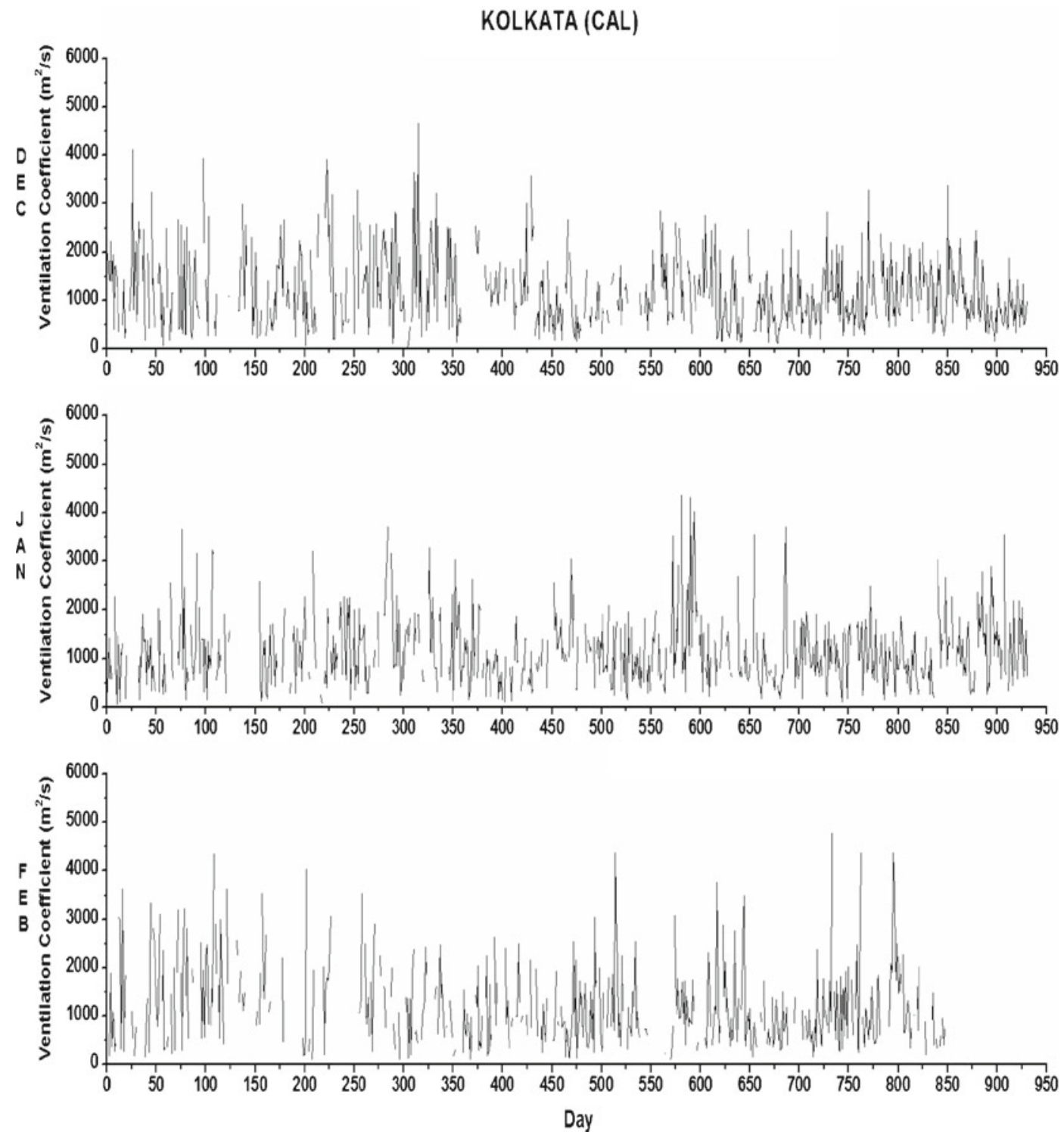

Figure 2(c). As in figure 2(a) but for Kolkata. 
over the 30-year period in all the months. Mixing depths seem to be decreasing slightly in all the months during the 30 years period over this station (BMB), the decrease being significant in December and January. Average wind speed through the mixing layer is around $2 \mathrm{~m} / \mathrm{s}$. Here too, a decreasing trend is seen in all the months through the 30-year period, the trends being significant in November, January and February. The mean mixing depth is around $600 \mathrm{~m}$ over Delhi (DLH) and wind speeds are $>4 \mathrm{~m} / \mathrm{s}$ though a decrease in strength is observed after the year 1990. In DLH, an increase in mixing depth is observed in all months except December while a significant decrease in wind speed is seen in all the months through the 30-year period, the decrease being prominent after 1990 . The variations in mixing depths and wind speed for Kolkata (CAL) are similar to that of BMB. A significant decrease in mixing depth in all months except November is seen. Wind speeds show an increasing trend in January, while in other months decreasing trend is observed. In the case of Chennai (MDS), the mixing depth generally increases up to the year 1980 in all the months though large fluctuations are seen in November and March. After 1980 , the variation is small especially in the peak winter season, i.e., December, January and February. The mean mixing depth is relatively the lowest over MDS, being about $308 \mathrm{~m}$. The wind speeds are stronger in MDS $(\sim 4-5 \mathrm{~m} / \mathrm{s})$ as compared to BMB and CAL especially in November, December and January although the strength is found to decrease through the 30-year period.

$\mathrm{BMB}$ and CAL show decreasing mixing depth in all the months in the 30-year period. In contrast, DLH shows increasing mixing depths in all the months except December. MDS too shows increasing mixing depths in all months especially
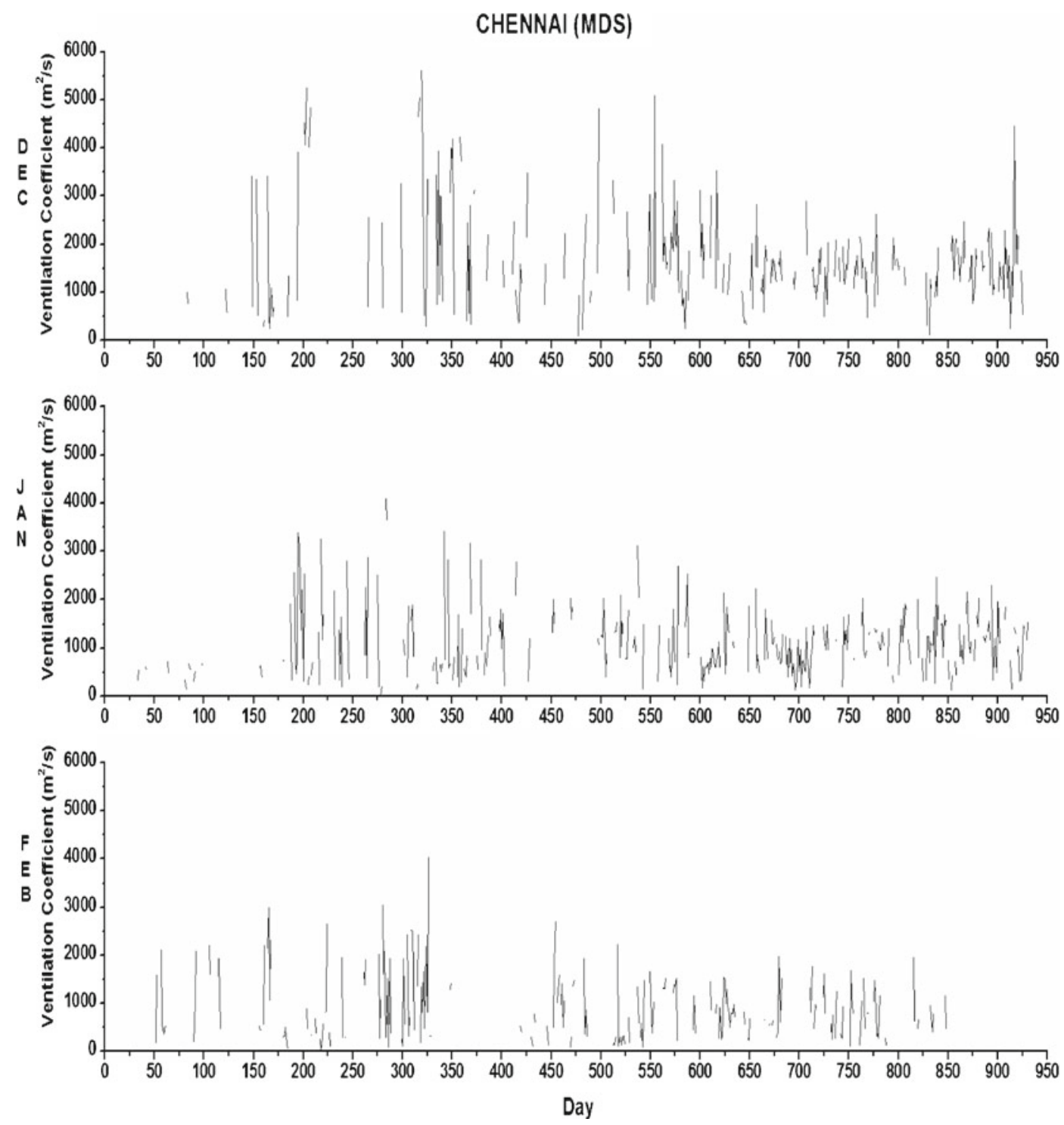

Figure 2(d). As in figure 2(a) but for Chennai. 
up to 1980. From figure 1(b), it can be seen that after 1985, mixing depths are either decreasing or remain constant with very small variability. The wind speeds however are decreasing in all the metros analyzed here during the 30-year period. Long term changes in mixing depths and wind speeds could possibly be due to changes in urban land use combined with changes in large scale circulation patterns. Although trends in mixing depths over a long period have not been reported, low mixing depths have been observed in winter months (irrespective of the technique used to compute mixing depths) at various locations in India by other researchers (Padmanabhamurthy and Mandal 1979; Vittal Murthy et al. 1980; Viswanadham and Santosh 1989; Devara and Ernest Raj 1993; Viswanadham and Pinaka Pani 1994; Krishnan and Kunhikrishnan 2004). Berman et al. (1999) studied the spatial and temporal variations of mixing depths in northeastern United States and found mixing depths at coastal locations to be particularly sensitive to the wind direction.

\subsection{Long-term trends in ventilation coefficient (VC)}

The daily derived mixing depths and observed wind speed through the mixing layer from the same station are used to compute ventilation coefficient (VC). The day-to-day variations in ventilation coefficients for the months December, January and February (peak winter months) for all the years are presented in figure $2(\mathrm{a}-\mathrm{d})$ for $\mathrm{BMB}, \mathrm{DLH}, \mathrm{CAL}$ and MDS, respectively. A small decreasing trend is observed in December, January and February for $\mathrm{BMB}$ (figure 2a). On most of the days the ventilation coefficient is $<2500 \mathrm{~m}^{2} / \mathrm{s}$ in December and
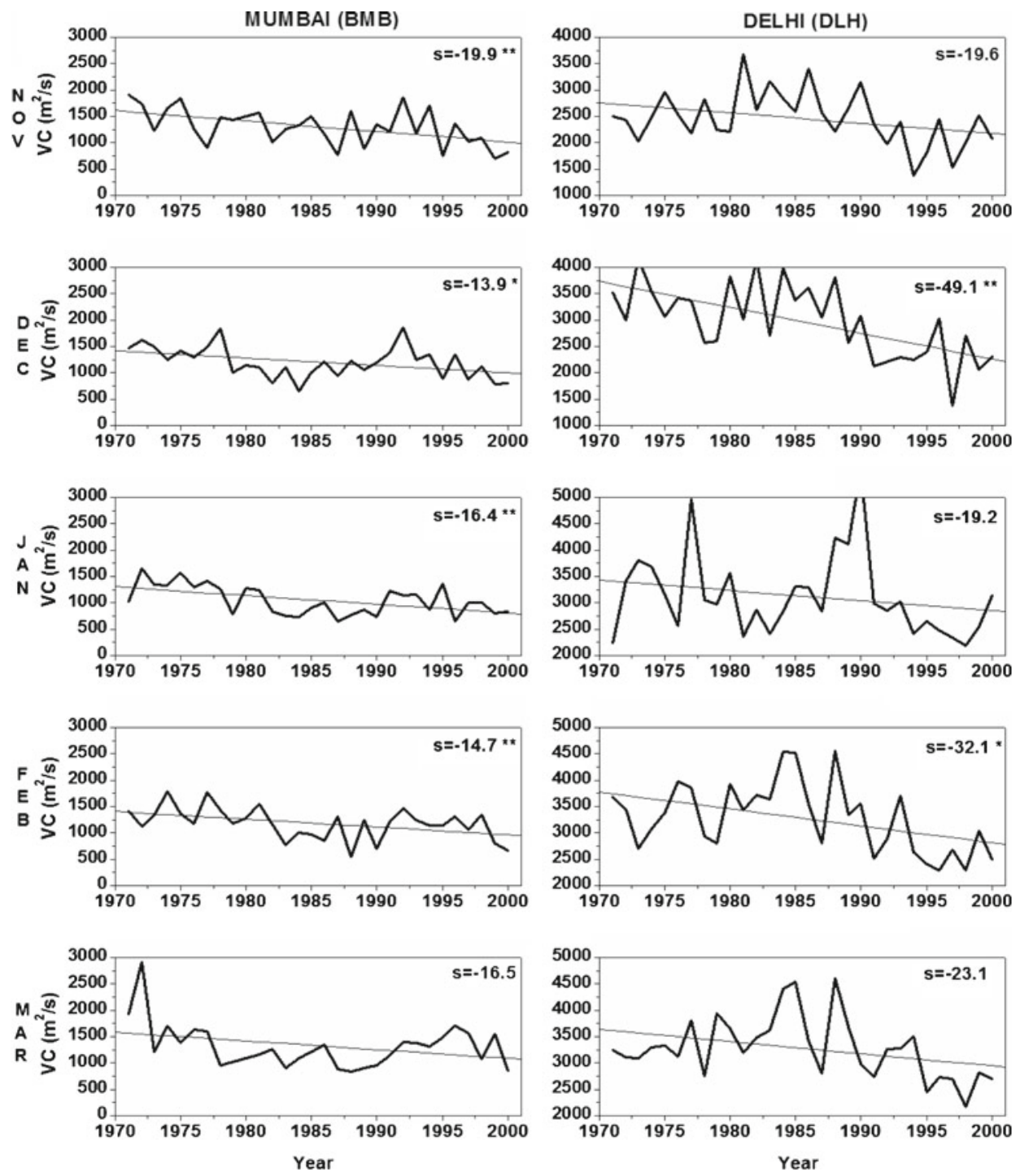

Figure 3(a). Annual variations in ventilation coefficient for the months November-March for Mumbai and Delhi (trends significant at $95 \%(99 \%)$ are marked by $*(* *))$. 
February and $<2000 \mathrm{~m}^{2} / \mathrm{s}$ in January though a few peaks can be seen in the three months with VC's reaching 4000-5000 $\mathrm{m}^{2} / \mathrm{s}$. In DLH (figure $2 \mathrm{~b}$ ) too, a decreasing trend in $\mathrm{VC}$ is observed in all the months. In contrast to $\mathrm{BMB}$, the $V C$ is frequently much higher ranging between 1500 and $5500 \mathrm{~m}^{2} / \mathrm{s}$ for many days in the months analyzed. Values of $V C>6500 \mathrm{~m}^{2} / \mathrm{s}$ are also observed on few occasions in all the months. Variations over CAL (figure 2c) are similar to those observed over BMB. Here too, a decreasing trend is seen in the three months though it is significant only in December and February. In December, the average value of $V C$ is in the range of $500-1500 \mathrm{~m}^{2} / \mathrm{s}$ though for a few days value of $3000 \mathrm{~m}^{2} / \mathrm{s}$ can be seen especially before 1980 . In January, values $>3000 \mathrm{~m}^{2} / \mathrm{s}$ can be seen for quite a few days between 1985 and 1990. A significant decreasing trend is observed in February though large data gaps exist especially between 1974 and 1986. Here average $V C$ values are below $2500 \mathrm{~m}^{2} / \mathrm{s}$. In MDS, ground inversions occur on fewer days as compared to the other metros studied here. Since we have taken the mixing depths to be the height of the surface inversion, the number of days for which $V C$ s were calculated is proportionately less. From the available data, we note that a significant decreasing trend is seen in December (figure 2d). In January and February, we observe increasing and decreasing trends respectively, which are not significant. Generally, the $V C$ s are $<2500 \mathrm{~m}^{2} / \mathrm{s}$ for most days when data is available. Since the sample size is very large for the daily variations ( $~ 930$ days in January and December and $~ 840$ days in February), the distribution of $(b / \mathrm{SE}(b))$ can be treated as a normal distribution. Here $b$ is the variable (ventilation coefficient in this case) and $\mathrm{SE}(b)$ is the standard error of $b$. We found $(b / \operatorname{SE}(b))>2$, so the hypothesis was rejected, i.e., trends were significant except at Chennai.

Annual variations in ventilation coefficient for the five months (November-March) are shown in figure 3(a) for BMB, DLH and in figure 3(b) for CAL, MDS. A linear best-fit line is drawn in all
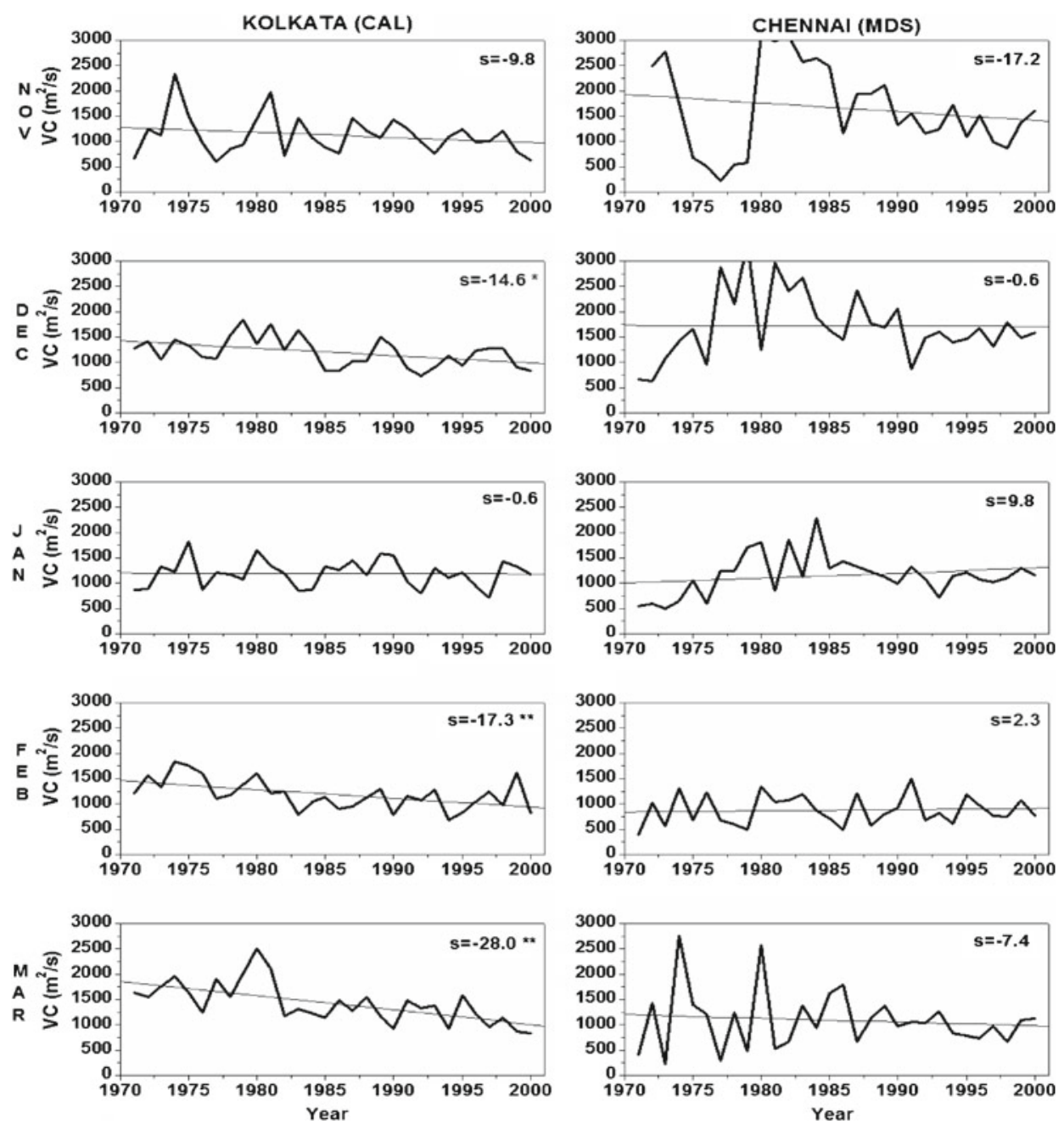

Figure 3(b). As in figure 3(a) but for Kolkata and Chennai. 
Table 1. Decadal increase in population (in millions).

\begin{tabular}{lccrr}
\hline Station & 1971 & 1981 & 1991 & 2001 \\
\hline Mumbai & 6.2 & 9.6 & 12.1 & 16.0 \\
Delhi & 3.9 & 5.8 & 8.0 & 13.0 \\
Kolkata & 6.8 & 7.4 & 11.2 & 13.4 \\
Chennai & 2.5 & 3.5 & 4.0 & 6.5 \\
\hline
\end{tabular}

the plots. A decreasing trend in $\mathrm{VC}$ is observed from 1971-2000 in all the five months for BMB with the slope ranging from -19.9 to $-13.9 \mathrm{~m}^{2} / \mathrm{s}$ per year. The decreasing trend is significant in all months except March. The average decrease in ventilation coefficient over Mumbai is about $15 \mathrm{~m}^{2} / \mathrm{s}$ per year. The decrease in $V C$ over this station may be attributed to the fact that both mixing depth and wind speed through the mixing layer show a decreasing trend in all months as seen in figure 1(a). Delhi too shows a decreasing trend in $V C$ in all months and they are significant in December and February. Here $V C$ decreases by 49 and $32 \mathrm{~m}^{2} / \mathrm{s}$ per year, respectively in December and February, the decrease being much higher than the decrease observed over BMB. The decreasing trend in $\mathrm{VC}$ over $\mathrm{DLH}$ despite the increasing mixing heights (figure 1a) is probably due to the significant decrease in the wind speed in all the months. The decreasing trend observed over these two metros (Mumbai and Delhi) is indicative of the deterioration of air quality in these large urban centers with ever increasing human activity.

A significant decreasing trend in $V C$ is observed over Kolkata in the months of December, February and March (figure 3b) with values of 14, 17 and $27 \mathrm{~m}^{2} / \mathrm{s}$ per year, respectively which are slightly lower than those observed over DLH. Like BMB,
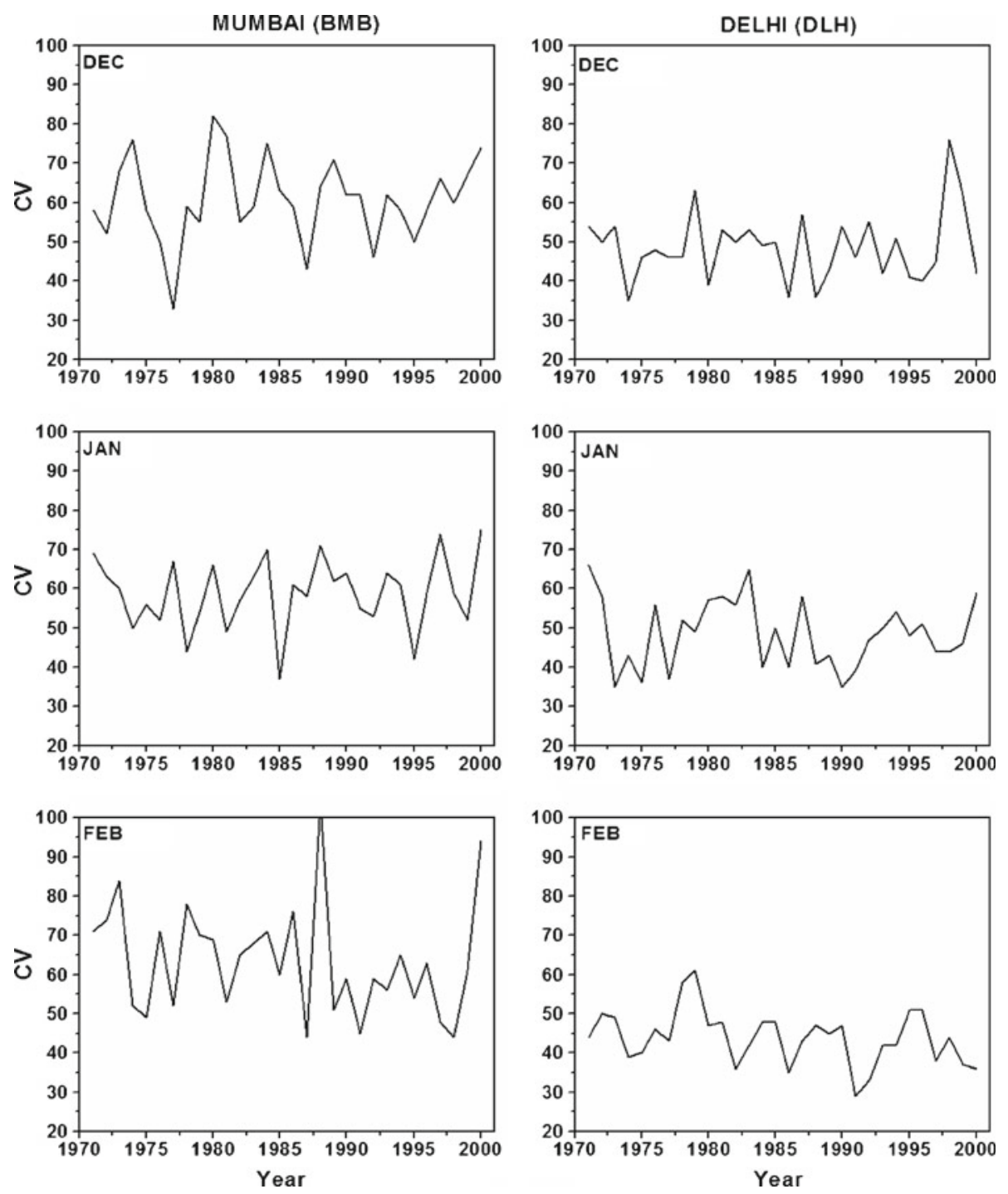

Figure 4(a). Coefficient for variation of ventilation coefficient for the months December, January and February for Mumbai and Delhi. 
in CAL too, the decrease in $V C$ can be attributed to the decreasing mixing height and wind speed in all the months (figure 1b). In MDS an increase of $\sim 10$ and $2 \mathrm{~m}^{2} / \mathrm{s}$ per year, respectively is seen in the months of January and February. In the other three months, a small decreasing trend is observed. However, none of the trends are statistically significant. Here the decreasing wind speed contributed to the decrease in $V C$ though mixing depths were increasing in all the months (figure 1b). For the annual variations considered here, the sample size is 30 for each month so $(b / \mathrm{SE}(b))$ follows 't' distribution with $(n-1)$ degrees of freedom, i.e., 29 in this case. Here, $(b / \mathrm{SE}(b))>1.699$ is the value for $\mathrm{t}_{29}$ at $5 \%$ level of significance. We have checked and found $|(b / \mathrm{SE}(b))|>1.699$, thus we reject the hypothesis, i.e., trends are significant wherever stated. Our results are in agreement with some earlier studies. Viswanadham and Santosh (1989) observed generally very low values of $V C$ in the early morning hours over south Indian region. The maximum values observed were $1000 \mathrm{~m}^{2} / \mathrm{s}$ in January and $2000 \mathrm{~m}^{2} / \mathrm{s}$ in July. Viswanadham and Pinaka Pani
(1994) have reported alarmingly low morning $V C$ s over north India, the worst season being October followed by January. Alappattu et al. (2009) studied the ABL features over Kharagpur $\left(22.32^{\circ} \mathrm{N}\right.$, $87.32^{\circ} \mathrm{E}$ ) and found that in general, $V C$ was low during the morning and evening hours and maximum during the early afternoon hours. The lowest $V C$ values observed corresponded with significantly low wind speeds and high aerosol mass concentrations. Elsewhere in the world, Ashrafi et al. (2009) estimated $V C$ for Tehran region (Iran) and found that the $V C$ values for spring and summer were higher than those for fall and winter. At Fort Simpson, Northwest Territories region, Yap (1974) found winter $V C$ extremely low on most days due to low mixing depths frequently coupled with light winds through mixing layer.

From figures $2(\mathrm{a}-\mathrm{d})$ and $3(\mathrm{a}, \mathrm{b})$, it is clear that $V C$ is decreasing over the 30 -year period in the peak winter months for BMB, DLH and CAL. In MDS too, a decrease is observed though in January and February a slight increase is seen. As evidenced from the decreasing trends in $V C$, it
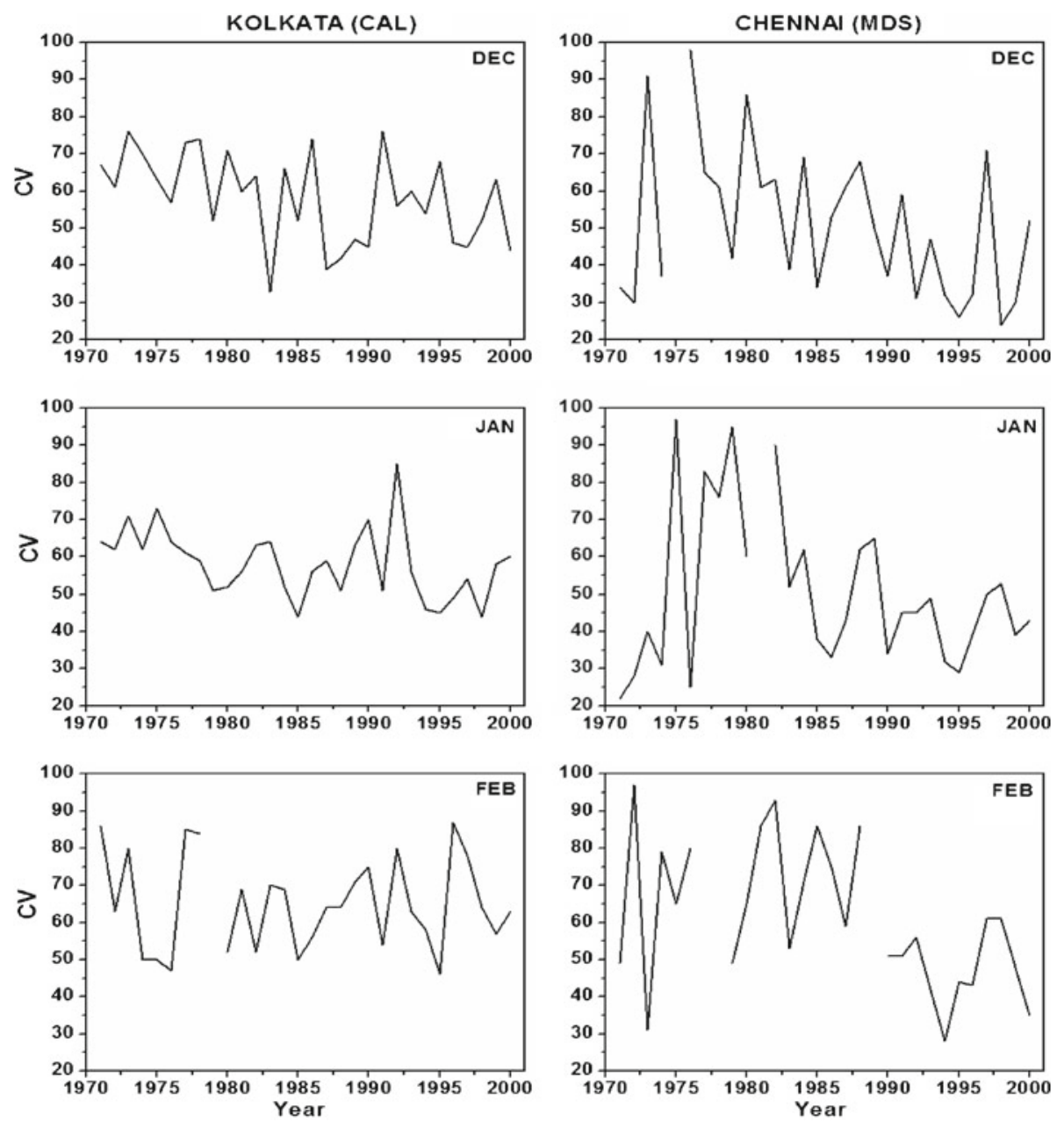

Figure 4(b). As in figure 4(a) but for Kolkata and Chennai. 
may be said that the air quality has continued to degrade in these large metropolitan cities over the last 30-year period. In the absence of a standard criteria for assessing pollution potential in India (Pandey et al. 2008), Gross (1970) criteria, i.e., mixing depth $\leq 500 \mathrm{~m}$ and wind speed $\leq 4 \mathrm{~m} / \mathrm{s}$ is applied to get a broad idea of the pollution potential over these metros. It is found that Delhi does not satisfy the criteria at all, indicating high pollution potential. With increasing human activity in Delhi with time, especially the vehicular emissions, smaller ventilation coefficients can lead to frequent pollution episodes like smog, etc. over this station. Consequent effects could be poor visibility and possible adverse influence on human health. Applying Gross (1970) criteria, Padmanabhamurthy and Tangirala (1990) also found high pollution potential in Delhi in all the seasons. The other three metros, viz., Mumbai, Kolkata and Madras, do on an average, satisfy the Gross (1970) criteria and can be assumed to have relatively lesser pollution potential. Although the computed $V C$ s are evidently decreasing over the years in these metros too, these are coastal stations with greater marine influence (like sea breeze) which is probably one of the reasons for the lower pollution potential.

The urban Indian population grew from 19.9\% in 1971 to $27.8 \%$ in 2001 (source: Census of India). The population increase in the four metros considered here is given in table 1. A sharp increase is observed in the last decade especially in Mumbai, Delhi and Kolkata. Growing urban population, industrialization, increased number of vehicles and anthropogenic sources are the main cause for increased pollutants trapped in the boundary layer leading to high concentration of surface pollutants. The decreasing ventilation coefficients limited the dilution and dispersal of pollutants leading to poor air quality.

\subsection{Variability in ventilation coefficient}

Daily estimated values of ventilation coefficient for each month at all the four stations are taken (data shown in figure $2(\mathrm{a}-\mathrm{d})$ ) and monthly mean and standard deviation are computed for different years. Coefficient of variation $(C V \%)$ is then computed to examine the variability in $V C$ over these locations. The year-to-year variations in $C V$ are presented for the three winter months (December, January, February) in figure 4(a) for BMB, DLH and in figure 4(b) for CAL, MDS. It is observed that variability is relatively higher over BMB and lower over DLH. The higher variability over BMB may be due to sea breeze circulation and synoptic scale wind systems while for DLH which is an inland station, the marine boundary layer influence tends to decrease and the variability is lower. Variability seems to be the lowest during February over DLH. $C V$ does not show any significant long-term trend at any of these locations. However, over MDS the $C V$ shows higher values during first half of the 30 -year period and lower values during later half period. These changes need more detailed investigation by looking into all other meteorological aspects like urbanization, etc.

\section{Conclusions}

Using 30 years radiosonde data, long term variations in ventilation coefficient over four major Indian metros, viz., Mumbai, Delhi, Kolkata and Chennai during peak winter months (December, January and February), show ventilation coefficient to be decreasing in the 30 -year period. The decrease is maximum in Delhi, with values 49 and $32 \mathrm{~m}^{2} / \mathrm{s} /$ year in December and February, respectively. In Mumbai, the average decrease is about $15 \mathrm{~m}^{2} / \mathrm{s} /$ year, while in Kolkata it is 14 and $17 \mathrm{~m}^{2} / \mathrm{s} /$ year in December and February, respectively. For both Mumbai and Kolkata, the decrease in ventilation coefficient may be attributed to decreasing mixing depths and wind speed. In case of Delhi, decreasing ventilation coefficient despite the increasing mixing depth may be attributed to the significant decrease in wind speed. In Chennai too, the decreasing wind speed contributed to the decrease in ventilation coefficient. The decreasing trends in ventilation coefficient through the 30-year period is indicative of the continued deterioration in air quality in these four metros. It also indicates high pollution potential especially in Delhi. Due to coastal influences in the other three stations, the pollution potential is comparatively lower.

\section{Acknowledgements}

The authors sincerely thank the Director, Indian Institute of Tropical Meteorology, for providing the facilities and support to carry out this work. They gratefully acknowledge the funding support from DST vide No. ES/48/ICRP/006/2005 through which the radiosonde data was procured. They are also thankful to the two anonymous reviewers whose comments and suggestions helped in the improvement of the manuscript.

\section{References}

Ananthakrishnan R and Soman M K 1992 Inconsistencies in the mean fields of temperature, geopotential height and winds over the Indian aerological network during JulyAugust; Mausam 43(2) 199-204. 
Alappattu D P, Kunhikrishnan P K, Aloysius M and Mohan M 2009 A case study of atmospheric boundary layer features during winter over a tropical inland station Kharagpur $\left(22.32^{\circ} \mathrm{N}, 87.32^{\circ} \mathrm{E}\right) ;$ J. Earth Syst. Sci. 118(4) 281-293.

Ashrafi K, Shafie-Pour M and Kamalan H 2009 Estimating temporal and seasonal variation of ventilation coefficients; Int. J. Environ. Res. 3(4) 637-644.

Attri S D, Siddartha Singh, Mukhopadhyay B and Bhatnagar A K 2008 Atlas of hourly mixing height and assimilative capacity of atmosphere in India; Met Monograph No. Environment Meteorology-01/2008.

Berman S, Ku J-Y and Rao S T 1999 Spatial and temporal variation in the mixing depth over the northeastern United States during the summer of 1995; J. Appl. Meteorol. 38 1661-1673.

Devara P C S and Ernest Raj P 1993 Lidar measurements of aerosols in the tropical atmosphere; Adv. Atmos. Sci. $10365-378$.

Ernest Raj P and Devara P C S 1992 Laser radar application to air pollution potential measurements during post sunset period; J. Optics 21(4) 87-92.

Goyal P, Anand S and Gera B S 2006 Assimilative capacity and pollutant dispersion studies for Gangtok city; Atmos. Environ. 40(9) 1671-1682.

Gross E 1970 The National Air Pollution Potential Forecast Program; ESSA technical memorandum, WBTM NMC 47.

Holzworth G C 1967 Mixing depths, wind speeds and air pollution potential for selected locations in the United States; J. Appl. Meteorol. 6 1039-1044.

Kothawale D R and Rupa Kumar K 2002 Tropospheric temperature variation over India and links with the Indian summer monsoon; Mausam 53 289-308.
Krishnan P and Kunhikrishnan P K 2004 Temporal variations of ventilation coefficient at a tropical Indian station using UHF wind profiler; Curr. Sci. 86(3) 447-451.

Manju N, Balakrishnan R and Mani N 2002 Assimilative capacity and pollutant dispersion studies for the industrial zone of Manali; Atmos. Environ. 36 3461-3471.

Padmanabhamurthy B and Mandal B B 1979 Climatology of inversions, mixing depths and ventilation coefficients at Delhi; Mausam 30(4) 473-478.

Padmanabhamurthy B and Tangirala R S 1990 An assessment of the assimilative capacity of the atmosphere at Delhi; Atmos. Environ. 24A(4) 845-848.

Pandey A C, Murty B P and Das R R 2008 Some aspects of air pollution climatology of Raipur and Korba; Indian J. Sci. Technol. 1(5) 1-8.

Srivastava H N, Dewan B N, Dikshit S K, Prakash Rao G S, Singh S S and Rao K R 1992 Decadal trends in climate over India; Mausam 43 7-20.

Stack Pole J D 1967 The air pollution potential forecast program; ESSA technical memorandum, WBTM NMC 43.

Viswanadham D V and Santosh K R 1989 Air pollution potential over south India; Bound.-Layer Meteorol. 48 299-313.

Viswanadham D V and Pinaka Pani V V S N 1994 Atmospheric dispersal capacity over north India; Theor. Appl. Climatol. 48 179-185.

Vittal Murthy K P R, Viswanadham D V and Sadhuram Y 1980 Mixing heights and ventilation coefficients for urban centres in India; Bound.-Layer Meteorol. 19 $441-451$.

Yap D 1974 A preliminary investigation of winter air pollution potential at Fort Simpson, Northwest Territories; Atmosphere 12(2) 62-68. 